\title{
Apresentação da integração de um jogo educativo para crianças com hemofilia com um Chatterbot
}

\author{
Roberta M. Matsunaga ${ }^{1,2}$, Lucas L. Padula ${ }^{1}$, Elenilson dos S. Pereira ${ }^{1}$, Marcos A. \\ F. Borges ${ }^{1}$ \\ ${ }^{1}$ Laboratório de Informática, Aprendizagem e Gestão/ FT (LIAG) - Faculdade de \\ Tecnologia - Universidade Estadual de Campinas (FT/UNICAMP) - Limeira - SP - \\ Brasil. \\ ${ }^{2}$ Fundação Centro de Pesquisa e Desenvolvimento em Telecomunicações (CPqD) \\ robertamatsunaga@gmail.com, \{1117729, el16678\}@unicamp.br, \\ marcos.borges@ft.unicamp.br
}

\begin{abstract}
This article describes the integration of an educational game, titled Hemotion, with a Chatterbot specialist in hemophilia, called Dr. Remus Philius. The intention is to build an educational tool to assist children with hemophilia further understand the concepts of the disease and its requirements and limitations.
\end{abstract}

Resumo. Este artigo descreve a integração de um jogo educativo, intitulado Hemotion, com o Chatterbot especialista em hemofilia Dr. Remus Philius. A intenção é a construção de uma ferramenta educativa para auxiliar crianças com hemofilia a entender mais os conceitos da doença bem como suas exigências e limitações.

\section{Introdução}

A hemofilia é uma doença hemorrágica hereditária com herança recessiva ligada ao cromossomo X. Como consequência, a doença acomete quase que exclusivamente pessoas do sexo masculino. Mulheres podem ser portadoras assintomáticas do gene que causa a hemofilia [Hegeman et al. 2011]. As principais características clínicas da hemofilia são sangramentos, principalmente em articulações e músculos, normalmente desencadeados por traumas. Meninos com hemofilia enfrentam diversas dificuldades, sobretudo em decorrência de sua limitação nas atividades físicas e recreativas. Essas crianças necessitam de frequentes administrações endovenosas do fator deficiente, o que causa desconforto e dor [Hegeman et al. 2011].

O desenvolvimento de material educativo, sobretudo de forma lúdica e interativa, é uma ferramenta importante para ajudar ao paciente compreender, aceitar e participar das questões envolvendo a doença. Neste sentido, o presente projeto teve como foco o desenvolvimento de um jogo educativo, utilizando os meios de informática, direcionado às crianças de 5 a 12 anos portadoras ou não de hemofilia, cujo tema central seja o entendimento das questões relacionadas à hemofilia. 
O jogo, intitulado Hemotion, tem como objetivo auxiliar crianças com hemofilia no aprendizado sobre a doença e conscientizá-las em relação aos cuidados e restrições que enfrentarão por toda a vida. Ao longo do jogo são salientadas atitudes corretas a serem seguidas. A intenção é que a criança aprenda se divertindo e que o conhecimento seja construído de forma interativa. Está integrado ao Hemotion um Chatterbot denominado Dr. Remus Philius, com base de conhecimento especializada em hemofilia. Serão apresentados nas próximas seções o Hemotion, o Chatterbot e a integração entre ambos. O trabalho termina com uma seção apresentando conclusões. .

\section{Jogo Educativo Hemotion}

O jogo Hemotion foi construído na plataforma Adobe Flash e está disponível na Internet, possibilitando às crianças com hemofilia acessá-lo de qualquer localidade e em qualquer horário. A equipe envolvida ao longo do desenvolvimento é multidisciplinar, envolvendo profissionais de Computação, Saúde e Educação.

A metodologia de ensino em que o jogo foi inspirado é chamada "Learning by Teaching" (LBT). Segundo a LBT, o aprendiz é colocado na posição de um tutor. O tutor obterá mais conhecimento através do ato de ensinar [Katzlberger, 2005]. No caso do Hemotion, o tutor é representado pela criança que joga e o tutorado é o personagem do jogo, que representa uma criança com hemofilia.

Durante o desenvolvimento da interface do jogo, crianças com hemofilia foram envolvidas em três dinâmicas promovidas pela equipe multidisciplinar. A intenção foi promover o Design Participativo na construção da interface. Nessa abordagem, as crianças com hemofilia, no papel de usuários finais do jogo, auxiliaram os desenvolvedores no processo de construção do design do jogo educativo [Walsh 2012].

A primeira dinâmica realizada, intitulada BrainDraw, teve por intuito realizar a prototipação do sistema com a participação dos próprios usuários. A prototipação objetiva realizar esboços de modelos que compõem a interface do produto em questão [Melo et al., 2008]. Como resultado da dinâmica, foram obtidos muitos desenhos candidatos para compor a interface do jogo. A Figura 1 traz um exemplo da composição realizada para formar o personagem principal do jogo, chamado João Ventura. Na Figura 2 é possível visualizar a formação do personagem Fator de Coagulação.

A avaliação da interface do jogo também foi realizada com a ajuda de crianças com hemofilia. A segunda dinâmica, chamada Avaliação Heurística Participativa tem o intuito de mensurar a usabilidade de um sistema através do uso de regras específicas. É uma técnica barata, rápida e efetiva de avaliar a interface de um sistema [Muller et al. 1998]. A dinâmica contou com 5 crianças com hemofilia com idades entre 5 e 8 anos e teve resultados positivos, mostrando o que podia ser melhorado ou modificado no jogo para atender às necessidades das crianças com hemofilia. 

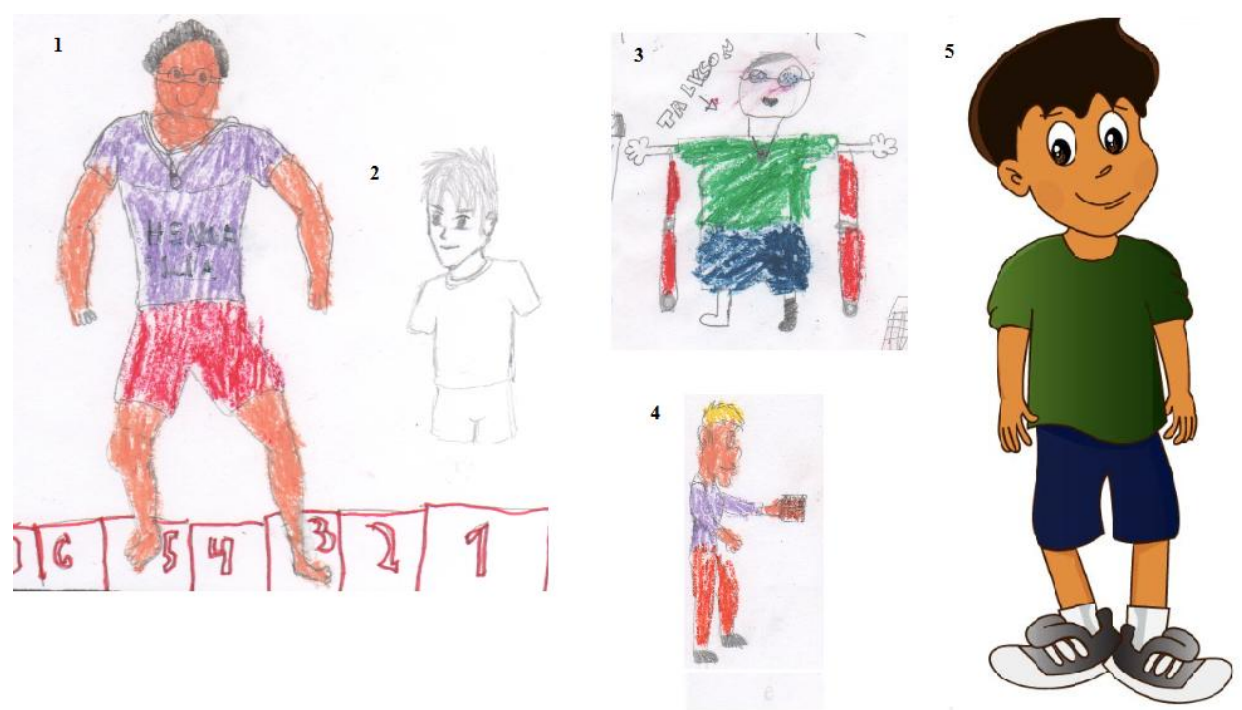

Figura 1: Personagem com hemofilia João Ventura [Matsunaga, et. al, 2012a].

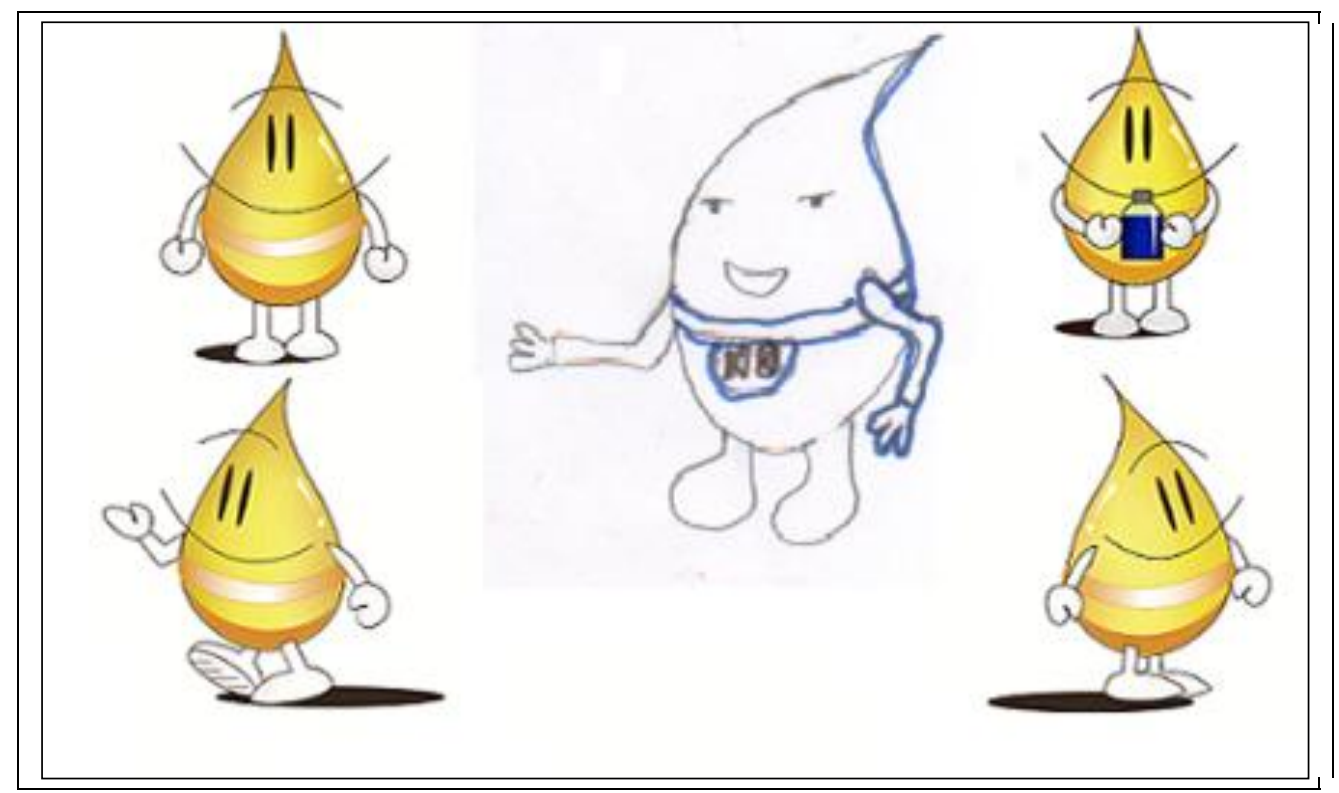

Figura 2: Personagem Fator de Coagulação [Matsunaga, et. al, 2012a].

Por fim, foi realizada uma última dinâmica para avaliar a qualidade e detectar possíveis erros no jogo. A dinâmica Teste Beta é um tipo de Teste de Validação é realizado nas instalações do usuário e conta com a participação do desenvolvedor [Pressman, 2000, p.482]. Esta dinâmica teve um diferencial importante para o projeto: contou com a participação de crianças em idade pré-escolar que não eram portadoras de hemofilia. Essas crianças, no contexto da utilização do jogo, representavam o perfil de irmãos, amigos ou parentes de uma criança com hemofilia que utilizam o jogo para aprender mais sobre a doença. No total, participaram dessa dinâmica três crianças com hemofilia com idades entre 5 e 8 anos e quinze crianças que não eram portadoras de hemofilia com idades entre 5 e 6 anos. $O$ resultado do trabalho realizado nas três 
dinâmicas foi crucial para o projeto, pois foi possível verificar qual o entendimento que uma criança que não é portadora da hemofilia tem sobre a doença após jogar o Hemotion.

O conjunto de dinâmicas auxiliou os desenvolvedores a construir a interface do Hemotion [Matsunaga e Borges, 2012a]. Na primeira tela do jogo, o jogador precisa selecionar o tipo de hemofilia que tem: A ou B. Isto é importante, pois, nesta tela, é possível detectar se a criança sabe ou não tipo de hemofilia que tem. Caso não saiba, essa parte do jogo irá incentivá-la a questionar os respectivos pais ou responsáveis para obter mais informação sobre a doença. O jogo segue com a apresentação da família do personagem João Ventura e informando ao jogador que o personagem vive no interior do Brasil. Essas informações não têm nenhuma conotação no decorrer do jogo mas, auxiliam o usuário a conhecer mais o personagem principal e o meio em que vive. $\mathrm{Na}$ Figura 3 é possível visualizar a família que é composta pelo pai, mãe, irmão e irmã. João Ventura é o único da família que tem hemofilia. A ideia é transmitir ao jogador a mensagem de que a mãe precisa cuidar de outros irmãos e não tem o tempo integral para dedicar-se ao filho com hemofilia, o que pode ser um problema para uma criança nesta situação.

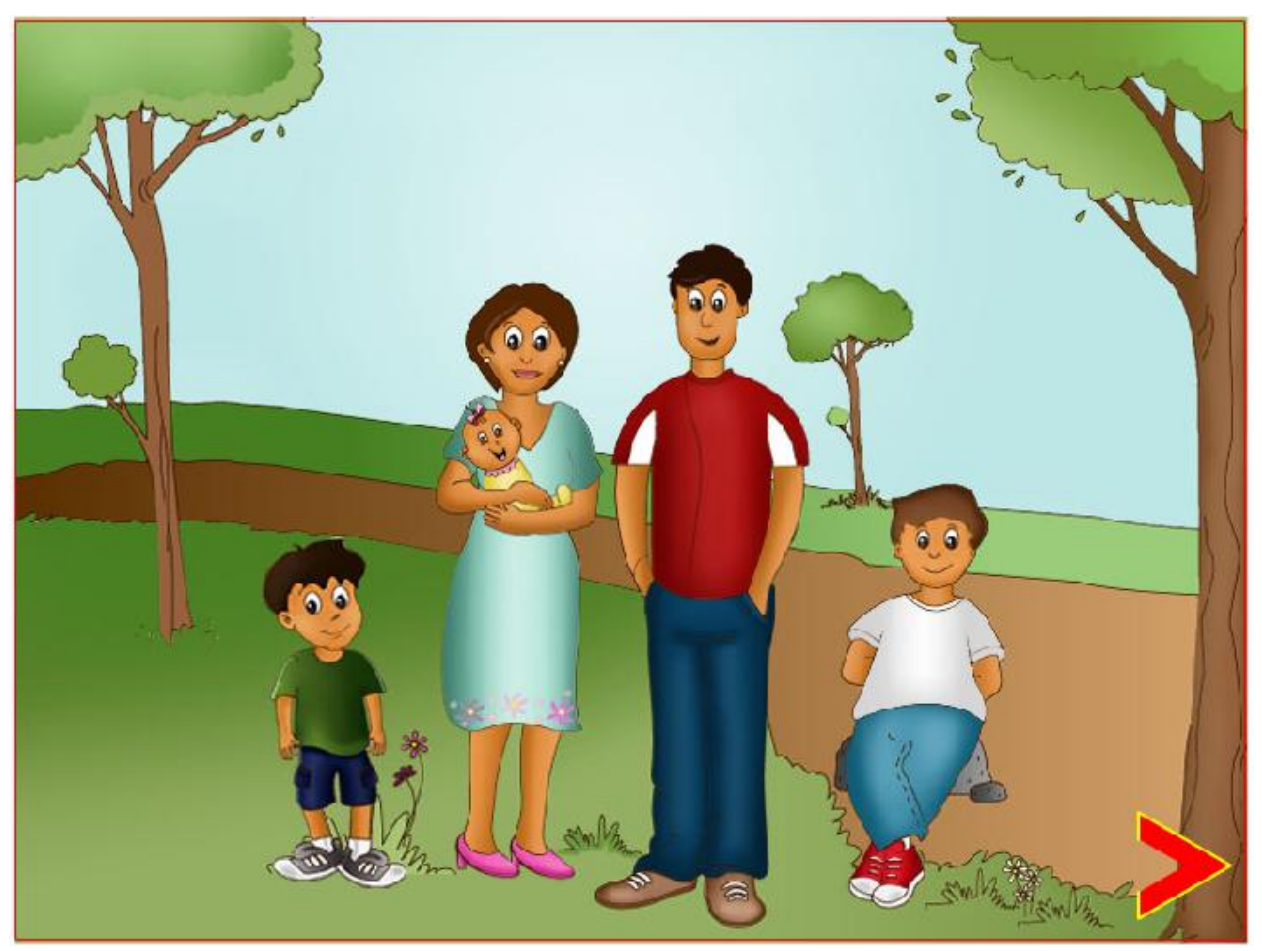

Figura 3: Família do personagem com hemofilia.

Ao longo do jogo é exibido o cotidiano do personagem com hemofilia: ele acordando, tomando banho, tomando café, escovando os dentes, enfim fazendo as atividades e necessidades diárias de uma criança normal. A Figura 4 mostra João Ventura acordando. $\mathrm{O}$ objetivo dessa contextualização é trabalhar na criança o conceito de que uma criança hemofílica é uma criança com uma vida normal. 


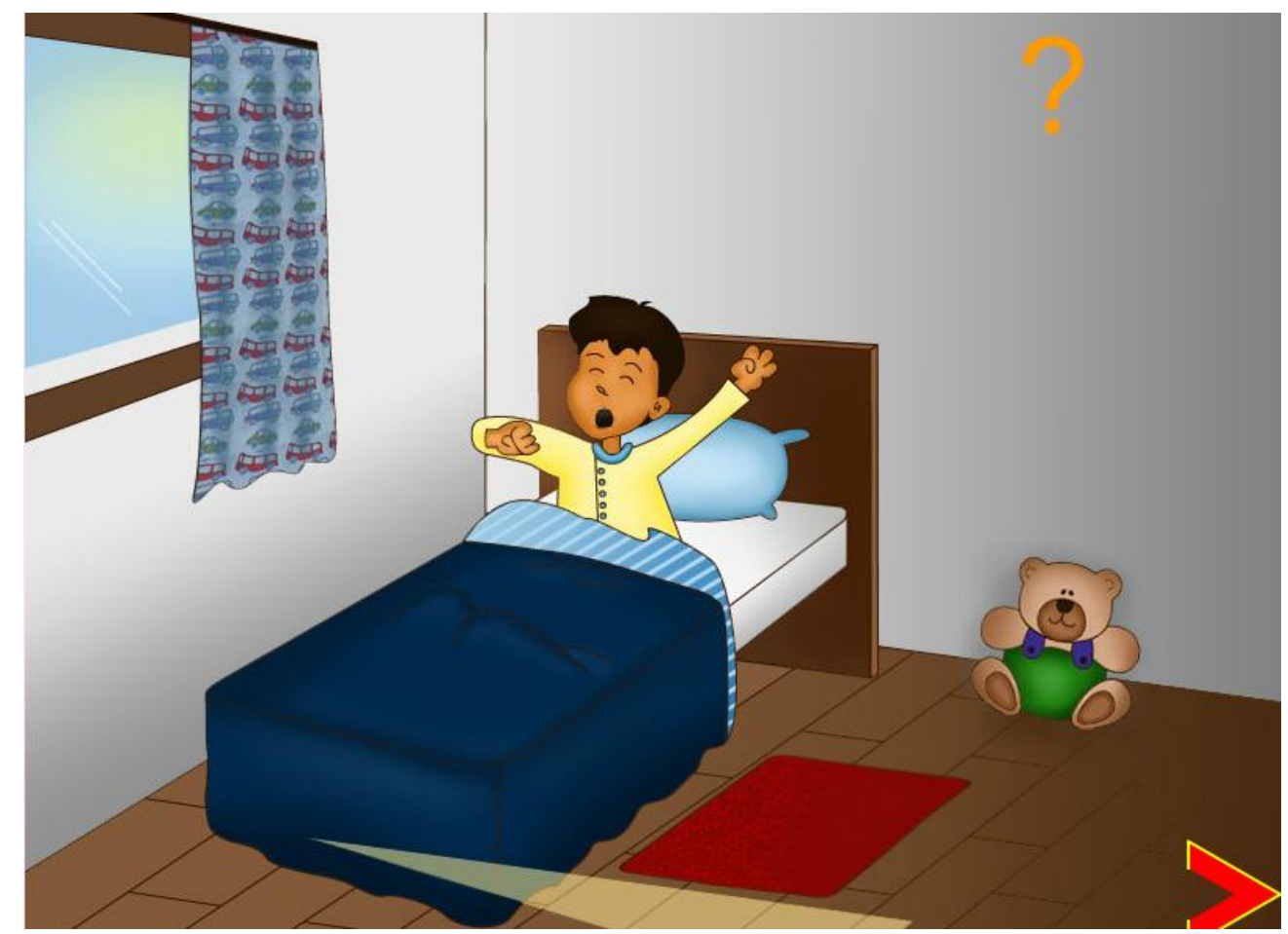

Figura 4: João Ventura acordando. No começo do jogo é exibido o cotidiano do personagem.

A primeira problemática que o personagem terá de enfrentar no jogo é escolher se vai ou não tomar fator de coagulação de forma preventiva. $O$ jogador, neste momento, atua segundo a LBT, ajudando o personagem a fazer a opção. Essa ação é exibida na Figura 5.

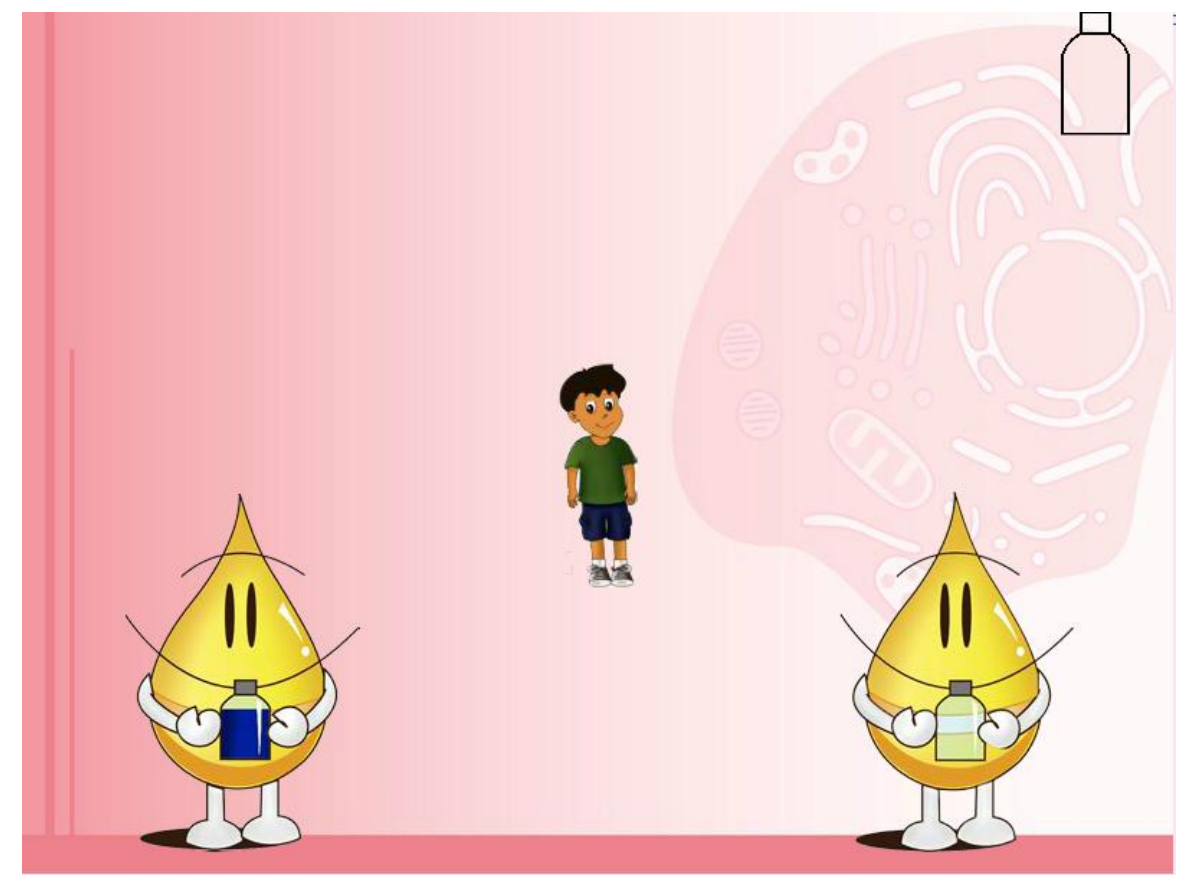

Figura 5: Primeira problemática do jogo, onde o jogador deve escolher tomar ou não fator de coagulação. 
O personagem se dirige à escola. Lá, João Ventura aprende um pouco mais sobre a hemofilia. A Figura 6 exibe uma captura de tela de um vídeo que a professora apresenta em sala para ele, que ilustra o processo de coagulação de uma pessoa normal e de uma pessoa com hemofilia.

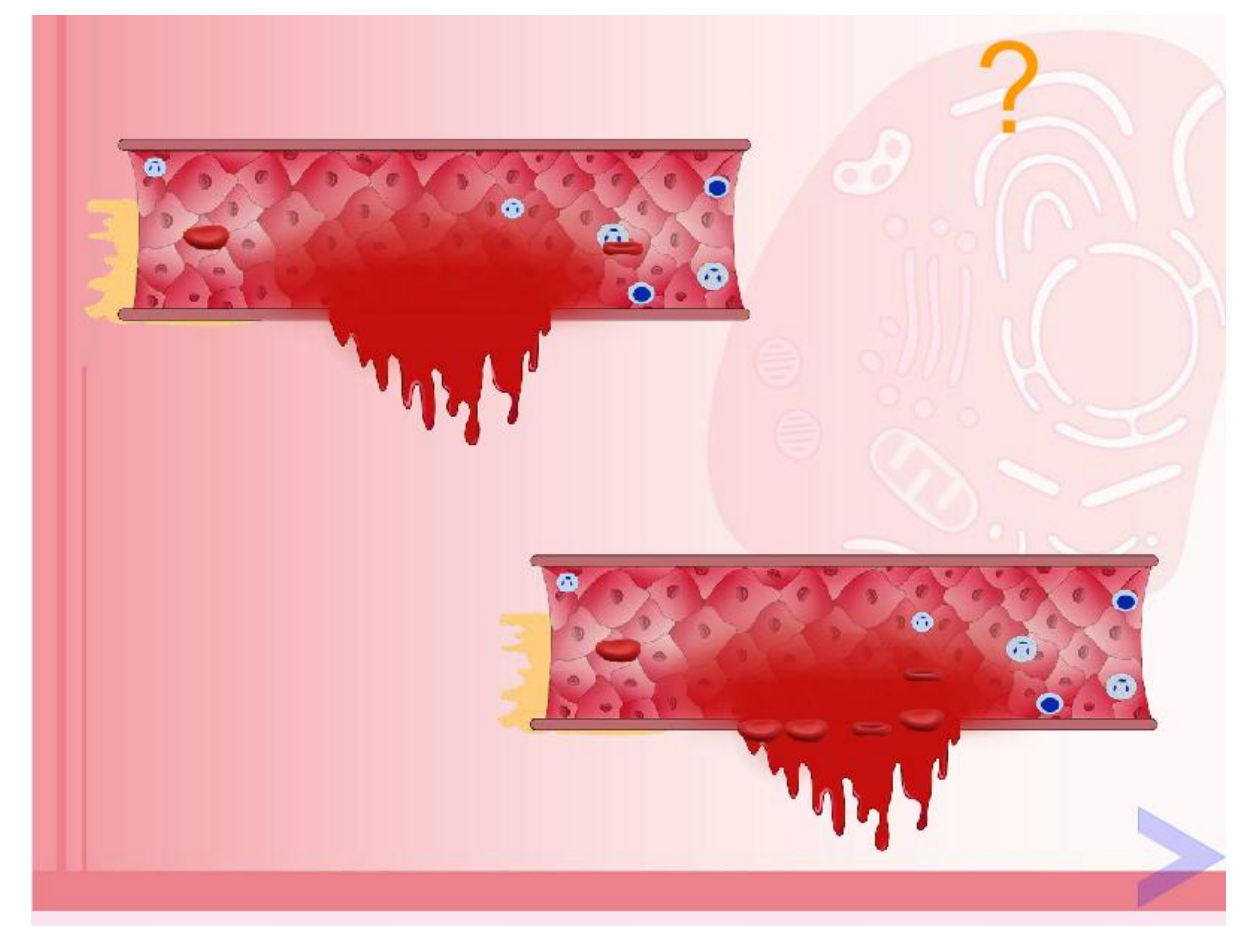

Figura 6: Demonstração do processo de coagulação de uma pessoa normal e de uma pessoa com hemofilia.

Após essa opção o personagem continua em suas atividades diárias como ir à escola, estudar e interagir com seus colegas. As atividades que poderá praticar no decorrer do jogo dependem diretamente de tomar ou não fator no momento correto. Caso o jogador selecione não tomar fator de coagulação e jogar futebol, por exemplo, o personagem acabará se machucando e não poderá praticar natação na fase seguinte.

Ao longo do jogo foram desenvolvidos 'mini-games', buscando tornar o Hemotion mais lúdico e motivador. Os mini-games são jogos interativos que permitem ao usuário jogar futebol, bolinha de gude, quebra cabeça, etc. A Figura 7 exibe a tela do 'mini-game' quebra cabeça.

Durante o jogo, ações do cotidiano de uma criança com hemofilia se misturam com ações do cotidiano de uma criança normal. A intenção é demonstras às crianças com hemofilia que o seu cotidiano de estudos, afazeres e brincadeiras pode ser normal. A doença exige um certo cuidado com as limitações e as aplicações endovenosas de fator mas, se a criança prosseguir com a forma adequada de tratamento, pode levar uma vida normal. 


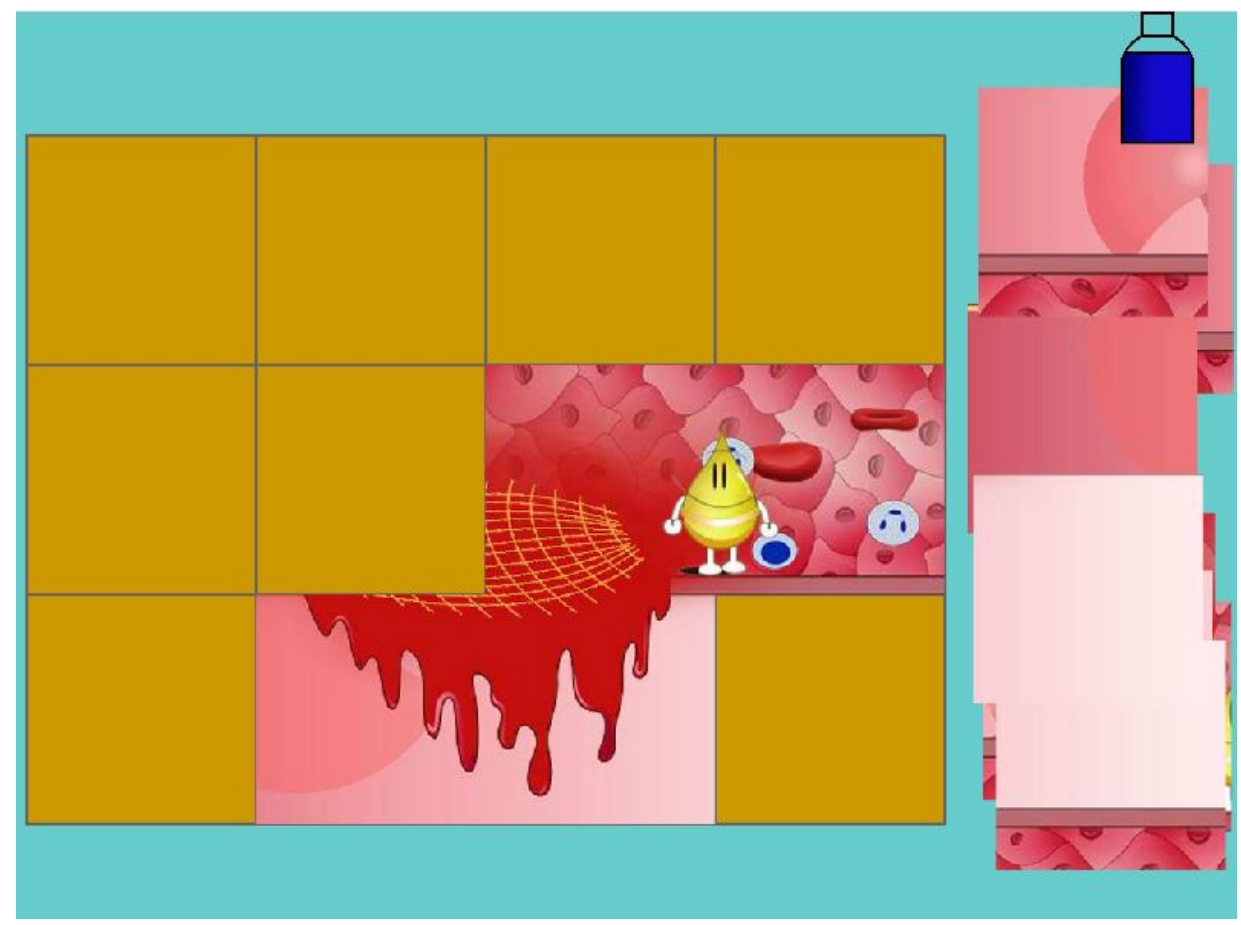

Figura 5: Mini-game quebra-cabeça.

\section{Chatterbot Dr. Remus Philius}

A palavra Chatterbot deriva da junção das palavras Chatter, palavra de origem inglesa que significa 'aquele que conversa', e robot, também do inglês, cuja tradução é robô. São programas de computador que interagem com humanos sobre um assunto específico [De Angeli, 2005]. O Chatterbot Dr. Remus Philius tem o intuito de interagir com uma criança com hemofilia, explicando-lhe alguns conceitos sobre a doença e como lidar com as problemáticas envolvidas.

A Figura 8 apresenta a arquitetura do Chatterbot desenvolvido.

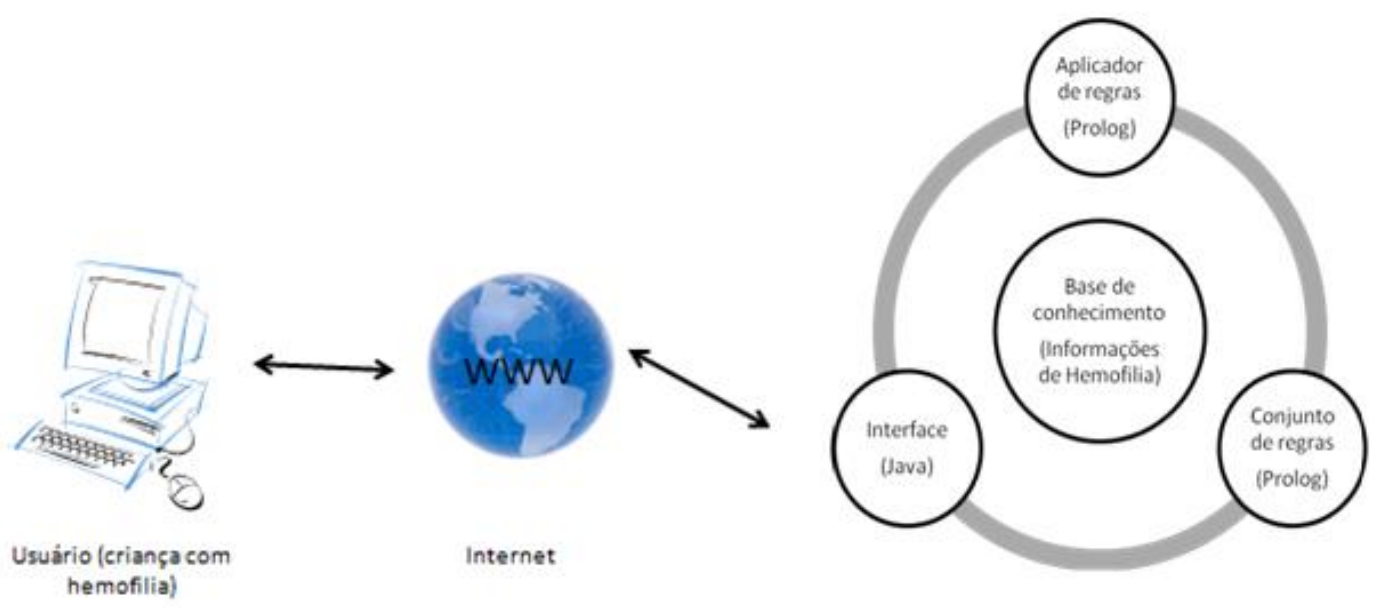

Figura 6: Arquitetura do Chatterbot desenvolvido. 
A interface de comunicação do Chatterbot com o usuário foi desenvolvida utilizando a linguagem de programação Java, o que permite que o acesso ao Chatterbot seja feito pela internet [Matsunaga e Borges, 2011; Matsunaga e Borges, 2012b]. A Figura 9 apresenta a interface do Chatterbot:

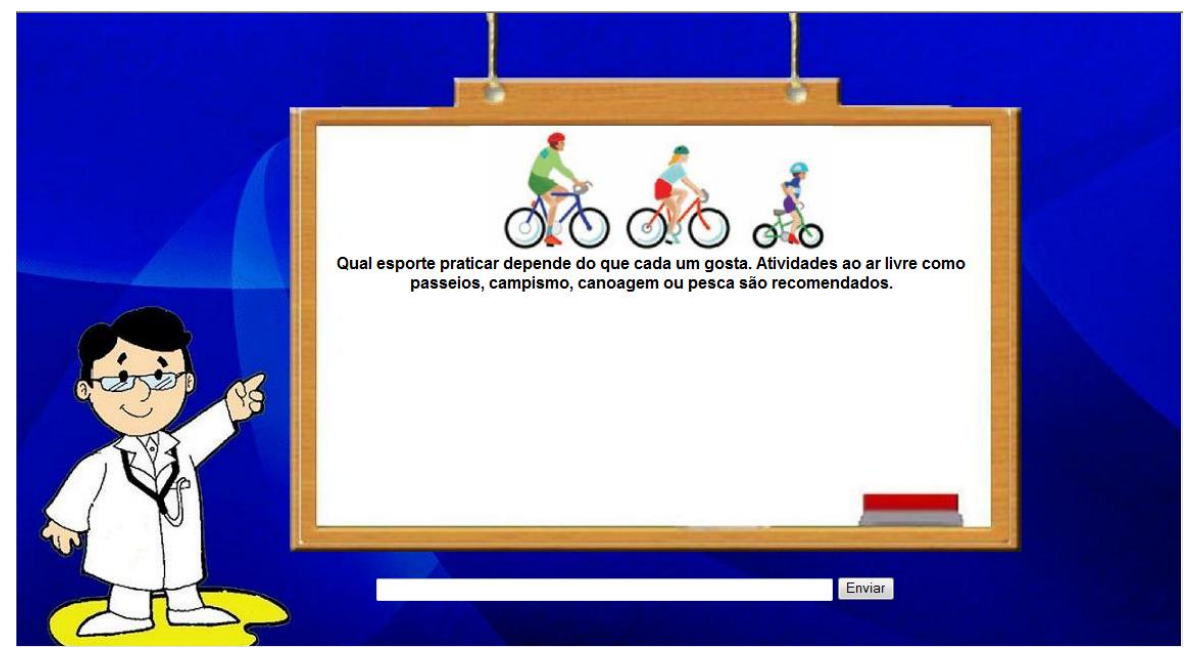

Figura 7: Interface do Chatterbot. Esta sendo demonstrado o comportamento do sistema ao responder a pergunta 'Quais esportes posso praticar?'.

Conforme exibido na Figura 9, o usuário digita a pergunta na caixa de texto que fica na parte inferior da tela e a resposta é exibida no quadro. De maneira geral, o que muda durante a interação do usuário com o Chatterbot é o texto que será exibido no quadro (que pode estar acompanhado de imagens e vídeos). Buscando uma maior motivação dos usuários, a expressão do rosto do Dr. Remus Philius (médico que está no canto inferior esquerdo) também é alterada, podendo representar sentimentos, como se estivesse nervoso, feliz, triste, com dúvida e indignado.

A base de conhecimento, que possui 450 frases, foi desenvolvida com a ajuda de material didático, cartilhas de hemofilia e profissionais da área. $\mathrm{Na}$ base de conhecimento fica armazenada toda informação que o chatterbot irá usar na interação com o usuário. É possível inserir, remover e alterar informações da base de conhecimento sem causar impactos às outras partes do programa. Portanto, conforme necessidade de novas informações, existe a possibilidade de manutenção dos dados.

As regras são aplicadas pela linguagem de programação Prolog. O conjunto de regras que determina o mecanismo de busca na base de conhecimento consiste na identificação de palavras-chave na pergunta que irão ser relacionadas às palavras-chave da base de conhecimento. Cada frase que forma a base de conhecimento está relacionada a uma ou mais palavras-chave.

\section{Integração do Hemotion com o Dr. Remus Philius}

Caso a criança usuária tenha alguma dúvida sobre a hemofilia enquanto está jogando o Hemotion, ela poderá acessar o Chatterbot e realizar perguntas. Para isso, basta ela 
pressionar o sinal de interrogação, apresentado em quase todas as telas e ilustrado na Figura 10.

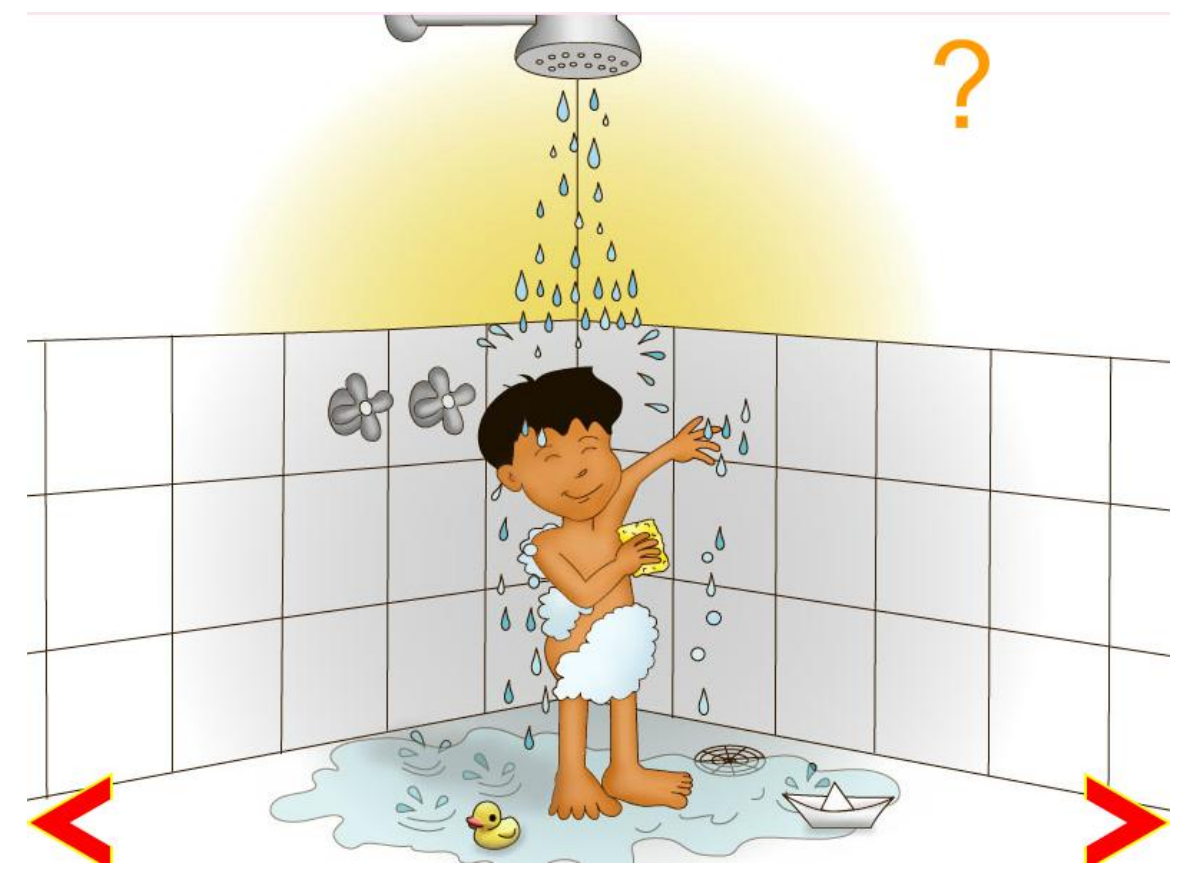

Figura 8: O jogador consegue acessar o Chatterbot através do jogo clicando no ponto de interrogação (?) na parte superior direita da tela.

\section{Conclusão}

O artigo apresentou o jogo educativo Hemotion, o Chatterbot especialista em hemofilia Dr. Remus Philius e a integração entre ambos. A união dos dois sistemas tem por objetivo incentivar crianças em idade pré-escolar e escolar a tomar atitudes corretas em relação à doença. A ideia é que o jogador conduza o personagem com hemofilia a ações corretas, aprendendo sobre a doença enquanto joga. Caso queira mais informações, é possível acessar o Dr. Remus Philius. O Chatterbot responderá então a todas as perguntas que são relacionadas à hemofilia.

O jogo foi avaliado em uma dinâmica de Teste Beta e os resultado mostraram que as crianças com hemofilia conseguiram aprender mais sobre a doença, suas necessidades e limitações [Matsunaga, 2013]. Futuramente, pretende-se realizar mais dinâmicas para estudar e avaliar a reação dos usuários perante o jogo.

\section{Agradecimento}

Este projeto é suportado por um patrocínio da Novo Nordisk Haemophilia Foundation. 


\section{$\overbrace{\text { novo nordisk }}$ \\ haemophilia foundation}

\section{Referências}

Hegeman, A. K. et al.. (2001) "Perceived competence in children and adolescents with haemophilia: an explorative study". Haemophilia. v.17, p. 81-89.

Katzlberger, T. (2005) “Learning by Teaching Agents". Tese (Doutorado em Filosofia) - Faculty of the Graduate School, Vanderbilt University.

Matsunaga, R. M.; Matta, M. A. P.; Ozelo, M. C.; Borges, M. A. F. "Development of a Chatterbot specialist in Hemophilia Care". WFH 12th International Musculoskeletal Congress. Dubai. 2011.

Matsunaga, R. M.; Borges, M. A. F. "Developing a Serious Game for childreen with hemophilia". In: IADIS Multi Conference on Computer Science and Information Systems 2012, 2012, Lisboa. Proceedings of the IADIS International Conference Game and Entertainment Technologies. p. 77-80. 2012a.

Matsunaga, R. M.; Borges, M. A. F. "Developing a Chatterbot specialist in hemophilia". In: IADIS Multi Conference on Computer Science and Information Systems 2012, 2012, Lisboa. Proceedings of the IADIS International Conference Intelligent Systems and Agents. p. 169-172. 2012 b.

Matsunaga. R. M., Borges, M.A.F., Moraes, R. L. O. "Desenvolvimento de um jogo educativo para crianças com hemofilia". Dissertação de Mestrado. 2013.

Melo, A. M.; Baranauskas, M.C.C. "Design para a Inclusão: Desafios e Proposta". Anais do IHC. Natal, RN. p. 19-22. 2006.

Muller, M. J.; Matheson, L.; Page, C.; Gallup, R. "Methods \& tools: participatory heuristic evaluation”. Interactions, v.5, n.5, p.13-18. 1998.

Pressman, R. S. "Software Engineering: A Practitioner's Approach". MacGraw-Hill Higher Education. Quinta edição. p. 482 - 483. 2000.

Walsh, G. (2010) "Developing DisCo: A distributed co-design, on-line tool", HCIL2010-18 [Relatório Técnico]. College Park, MD: Human-Computer Interaction Lab. 